\title{
GHILD LABORERS;
}

\section{ABUSE IS UNIVERSAL AT RAWALPINDI}

\section{DR. NOSHEEN ZAIDI, MBBS, MPH}

Assistant Professor Community Medicine,

Foundation University Medical College, Islamabad.

DR. SAIF-UD-DIN SAIF, MBBS, MPH

Assistant Professor Community Medicine,

Rawal Medical College, Rawalpindi.
DR. MAHMOOD AHMED

MBBS, MCPS, DPH\& DIH, M.Sc Med Admin

Professor\& HOD Community Medicine,

Foundation University Medical College ,Islamabad

\section{Dr. Wasif Khan}

MBBS, DPH, M.Sc Com.Med, M.Sc Med Admin

Associate Professor Community Medicine,

Foundation University Medical College ,Islamabad

ABSTRACT... Background: In Pakistan there are about 3.3 Million unprotected child laborers. They are constantly exposed to all kinds of dangers and abuse intimidating the future of the country. These child laborers are without the basic necessities of life including food, shelter, schooling and healthcare services, which has devastating effects on our socio-economic fabric. It is quite imperative to comprehend and unveil the perilous picture of the working conditions of child laborers and the abuse inflicted upon them at such an impressionable age. Design: Cross sectional study. Setting: Rawalpindi city including workshops, shops and streets of Rawalpindi. Period: January 2008-Dec 2008. Objective: To assess the presence of any Verbal, Physical and Sexual abuse among the child laborers at Rawalpindi city. Results: Out of the total sample of 700 study subjects $315(45 \%)$ of the Child laborers reported being abused whereas $385(55 \%)$ reported no abuse. Out of the fraction which reported to be abused the break up is as follows. $214(67.9 \%)$ reported verbal abuse, $75(23.8 \%)$ reported Physical abuse and $25(7.9 \%)$ reported sexual abuse. Conclusions: This study concluded that the child laborers are open to the elements of the adversities that come along with their work environment. The government should be urged to take necessary steps to trim down the abuse against child laborers and its frightening effects on their families, society and nation at large by constituting strict laws and ensuring their speedy implementation.

Key words:Labor, Abuse, Verbal, Physical and Sexual.

\section{INTRODUCTION}

Child abuse is a grave and complex physical, psychological and sociological problem that produces threatening results for a society and it occurs in epidemics world wide .Human right watch report says that 150 million girls and 73 million boys suffer abuse below the age of 18 years ${ }^{1}$. Millions of children are victims of non fatal abuse and neglect .In some studies between quarter and one half of children had gone under the frequent abuse by their care providers ${ }^{2}$.

Since few decades ago, the issue of child labor has gained international attention as a cause damaging their development ${ }^{3}$. Children are engaged in diverse forms of labor and their physical and psychological well being is compromised ${ }^{4}$. Working environment is the main cause of children ill health ${ }^{5}$. Child Labor enhances the deficiencies, poor health and poverty ${ }^{6}$. According to UNICEF 3,500 children die annually and abuse is a leading cause of death in children in developed world ${ }^{7}$. These child laborers are reported poisoned, amputations, skeletal deformities, serious skin and other infections, chronic lung disease, cancers, burns, and impairments to hearing ,vision and immune functions and also sexual transmitted infections ${ }^{8}$. These deprived child labors include children living on streets, refuge children ,working in restaurants or employed in industries are the most vulnerable group is round about 3.6 million ${ }^{9}$. However non-official estimate is 10 million are engaged in child labor predisposed to exploitation ,assault and sexual abuse ${ }^{10}$.

\section{METHODOLOGY}

A cross sectional study was conducted to assess the presence of any physical, mental, or sexual abuse due to their employment status. Research question is: What types of abuse are being faced by child laborers at various work places of Rawalpindi city including workshops, shops and streets of Rawalpindi for twelve months, from January 2008-Dec 2008.

\section{Methods}

700 child laborers (Boys) were interviewed using a pretested Close-ended questionnaire form, after getting prior permission of employers of child laborers. Study area included Pir Widhaee fruit market, Kamran market, 
Tipu road automobile workshops and China market of Rawalpindi, transport was arranged by Foundation University Medical College for data collection.

Study population was children between the ages of 4-18 years working in the vicinity of Rawalpindi. Sampling technique was non-probability; simple convenient sampling .Interviews were conducted, after obtaining an informed consent. A pretested structured questionnaire designed in the local language, was used to obtain information regarding socio-demographic features, verbal, physical and sexual abuse. Data collection: All child laborers present in their working environment were eligible for the study so as to get the desired sample size, and all the child laborers present during the survey were included in study.

\section{DATAANALYSIS}

All data was collected and processed with full confidentiality. Statistical analysis was performed using Statistical Software Package SPSS 17.0 (SPSS). Descriptive statistics were used to describe the data.

\section{RESULTS}

Most of the child laborers working in various localities of Rawalpindi city reported that they were being abused. Almost 44.7\% (314) of children replied positive about abuse at their work places. Highest abuse reported was verbal i.e. $67.8 \%$ (213), Second was physical 23.8\% (75) and lastly $7.9 \%$ (25) reported the worst form of abuse i.e. sexual.

\section{DISCUSSION}

This study reported that $47 \%$ child laborers faced different types of abuse. Out of them highest abused reported was verbal abuse i.e. $67.8 \%$ (213). Next was physical $23.8 \%$ (75). Similar to our results a study conducted in Pakistan, it was found that out of the total population of child laborers, that few about $7 \%$ suffered from illness/ injuries regularly and some $28 \%$ rarely ${ }^{11}$.

Several case-control and cohort study have reported association of impaired growth, poor health of child labor $^{12}$. In our study $7.9 \%$ (29) where sexually abused, while studies on child sexual abuse statistics vary between nations and survey reports, but all are
Abuse Reported by Child laborers

$\mathrm{N}=700$, Yes = $314(44.7 \%)$, No =386 (55.3\%)

$\begin{array}{cc}\text { Type } & \text { Frequency } \\ \text { Physical } & 75(23.8 \%) \\ \text { Verbal } & 213(67.8 \%) \\ \text { Sexual } & 25(7.9 \%) \\ \text { Total } & 314\end{array}$

consistently alarming. In Pakistan only $2.7 \%$ of sexual abuse cases are reported to police ${ }^{13}$. Child labor remains one of the most provocative and controversial challenges facing the world at the beginning of the 21st century. Further more child labor close links to poverty, poor health and broad-based social and economic progress. Lopez AD work shows that child labor can affect some of health indicators ${ }^{14}$. Gracitar and Lerir were also able to detect physical injuries they reported one third injuries of all injuries sustained in children were linked to occupation ${ }^{15}$.Work can expose children to physical and social environment conductive to high-risk sexual behavior .Child labor is significantly correlated to HIVIAIDS, interventions that reduce child labor could have direct health benefits ${ }^{16}$. The health effects of child labor on children and the correlation between current health and future health status are difficult to investigate and are compounded by short term versus and long term health consequences ${ }^{17}$.

Limitations of study are that child laborers were interviewed at their work place and as data were collected in workshops and markets therefore only boys where included; results can be different in other child workers. Although our findings indicate abuse among child labor more data are needed to develop better understanding of short and long term health problems associated with child labor .Most important, longitudinal studies are required to understand effects on individual child.

\section{Copyright@ 24 Sep, 2011.}

\section{REFERENCES}

1. Human Rights Watch .Events of 2007. World report 2008.

2. Global Estimates of Health Consequences due to 
Violence against Children, WHO 2006.

3. Sarwar M A. Muhammed W. Muhammed A .Why do parents make their children work? Evidence from multiple indicator cluster survey. IJAR. Vol 3.No. 2.March 2011.Part II: 545-549.

4. Mohammad U N, Mohammad H ,Bernard G G. Physical and Psychological implications of risky Child Labor:A study in Sylhet city ,Bangladesh. BDRWPS no .8 July 2009:1-19.

5. Khan, J. and Ejaz, R. The determinants of child labor a case study of Pakistan and Faisalabad (Pakistan) PhD thesis, Bahauddin Zakariya University, Multan.2003.

6. Jabari A L, David L. Parker, Charles 0 . Child Labor,Gender,and Health. Public Health Report. 2005. Vol5120 (6) Nov-Dec;642-648.

7. Launch Of The Innocent Report Card 5: A League Table Of Child Maltreatment Deaths in Rich Nations EMBARG0 10 GMT, 18 September 2003.

8. Thomas J S, Viven P, Maria L, Margaret A lynch, Francesca S .Child Labour vast problem whose effects on children s health remain unstudied. BMJ.2002 August 24;325(7361):401-403.

9. Pakistan pediatrics association and save the children, Sweden: Confronting Reality .Sexual exploitation and abuse in Pakistan. Asituation Analysis 2000. Pakistan.
10. Save the Children, Sweden: Commercial exploitation of children-A situational analysis, 2004-2005, Pakistan.

11. Sahil (NGO): Cruel Number Study on Child Sexual Abuse for 2004-2005, Islamabad, Pakistan.

12. Child labour situation in South Asia. International Programme on the Elimination of Child Labour. Human development report in South Asia 2004.

13. Hawadeh $\mathrm{H}$, Spencer N. Effect of work related variables on growth among working boys in Jordan. J Epidemiol Community Health 2003;57:154-158.

14. Lopez AD, Salamon J, ahmed O, Murray C JL. Life tables for 191 countries: data ,met and results. Global Program on evidence discussion no 9.Geneva, Switzerland: World Health Organization;2000.

15. Gracitor P L, Lerer LB. Child Labor and health report of a field investigations in Egypt Washington DC World Bank2000.

16. Paola R.Viviana M ,Flavia B , Furio R.The Health Impact Of Child Labor In Developing Countries: Evidence from Cross-Sectional Country Data. Am J Public Health .2007 February; 97 (2) :271-275.

17. Harper C, Marcus R, Moore K. Enduring poverty and the conditions of child hood ;life course and intergenerational poverty transmissions. World Dev 2003; 31:535-554.
Correspondence Address:

Dr Nosheen Zaidi, Asst. Professor,

Community Medicine Department.

Foundation University Medical College,

The Mall, DHA Phase 1, Islamabad.

noshaarif@yahoo.com
Article Citation:

Zaidi N, Saif S, Ahmed M, Khan W. Child laborers; Abuse is universal at Rawalpindi. Professional Med J Dec 2011;18(4):632-634.

\section{EFFECTIVE ACTION IS ALWAYS UNJUST.}

MAYA Angelou 